\title{
Electrochemical Characterization of Guanine and Guanosine Based Biosensors Over Multi-Walled Carbon Nanotube Modified Graphite Electrode
}

\author{
S. BABY GAYATHRI, P. KAMARAJ, M. ARTHANAREESWARI and S. DEVI KALA \\ Department of Chemistry, SRM University, Kattankulathur - 603203, India \\ kamaraj97@yahoo.co.in
}

Received 6 August 2014 / Accepted 5 September 2014

\begin{abstract}
Electroactive purine nucleobase, guanine and purine nucleoside, guanosine were immobilized over multi-walled carbon nanotubes (MWCNT) modified graphite electrode. The electrooxidation properties of purines were evaluated using differential pulse voltammetry. Mixtures of purine nucleobase and nucleoside in various concentrations were prepared and electrochemically immobilized over the working electrodes using positive potential difference. The anodic current at around $0.7 \mathrm{~V}$ was used as analytical signal for guanine. The influence of immobilization time, MWCNT concentration and purine concentration were evaluated and electrochemical mechanisms have been discussed. Special emphasis was given to study the stable recognition layer in a redox couple $\left(0.1 \mathrm{M} \mathrm{NaCl}\right.$ containing $\left.10 / 10 \mathrm{mM} \mathrm{K}_{3} \mathrm{Fe}(\mathrm{CN})_{6} / \mathrm{K}_{4} \mathrm{Fe}(\mathrm{CN})_{6}\right)$ using electrochemical impedance spectroscopy and cyclic voltammetry. Further, electrochemical interaction of immobilized purine structures over benzene substituted organic compounds were studied using DPV in $0.1 \mathrm{M}$ phosphate buffer, and $\mathrm{CV}$ and EIS in $0.1 \mathrm{M} \mathrm{NaCl}$ containing $10 / 10 \mathrm{mM} \mathrm{K}_{3} \mathrm{Fe}(\mathrm{CN})_{6} / \mathrm{K}_{4} \mathrm{Fe}(\mathrm{CN})_{6}$. The standardized and calibrated purine immobilized electrode could be potentially used as purine based biosensor for the electrochemical detection of benzene substituted organic compounds.
\end{abstract}

Keywords: Benzene substituted organic compounds, Cyclic Voltammetry, Differential Pulse Voltammetry, Electrochemical Impedance Spectroscopy, Multi-walled carbon nanotubes, Purine based biosensor.

\section{Introduction}

Purine nucleobase, guanine is one of the basic units of nucleic acid structure of DNA of living organisms. Down and his co-workers ${ }^{1}$ reported the optical and electrochemical properties of purine bases in nucleic acids. Since then interest has been generated among the electrochemists to explore the electrochemical characteristics of purine bases and its applications as a rapid, cheap and selective biosensor. Purine nucleobases and DNA strands have been reported to be immobilized over noble metals and carbon based electrodes. Initially, wide research has been performed in electrochemical immobilization of graphite and glassy carbon. In the later stage, focus were on the immobilization of purine bases over the modified electrode using metal complexes ${ }^{2}, \mathrm{PANI}^{3}, \mathrm{MWCNT}^{4}$ etc. to obtain better 
efficiency. Significant enhancement in the oxidation signals of purine bases over MWCNT coated carbon based electrodes have been reported due to its unique electrical property and high surface area.

Benzene and most of its derivatives have been reported to be highly toxic due to its carcinogenic and DNA damaging activity upon oxidation. The damaged DNA may be mutagenic or carcinogenic in vivo. The major DNA adduct formed by the oxidation of guanine base in nucleic acid includes hydroxy-, oxy- and deoxy- forms of guanine and guanosine. Toulene and its metabolites were found to form 8-oxy-7,8-dihydroxy-2'deoxyguanosine upon DNA damage in testes of the male rats ${ }^{5}$. Formation of 8-hydroxyguanine (8-OHGua) has been identified during DNA extraction using phenol ${ }^{6}$. 8-hydroxy-2'deoxyguanosine and double strand breakage were noticed in rat liver slices after its interaction with bromobenzene ${ }^{7}$. o-Toluidine metabolites increased 8-oxo-7-, 8-dihydro2'deoxyguanosine formation in calf thymus DNA in the presence of copper ions resulting in the expression of carcinogenicity ${ }^{8}$. The presence of hydroquinone and copper ions was found to have an impact on DNA by inducing both the single and double strand breaks ${ }^{9}$ and formation of 8-hydroxydeoxyguanosine resulting in genetic disorders and myelotoxicity ${ }^{10}$. Ediberto et al., examined the potential of 2,4-Dinitrotoulene to damage DNA of primary rat hepatocytes and suggested that the damage of DNA to play a major role in carcinogenicity ${ }^{11}$. All these 6 compounds which were known to produce guanine based DNA adducts upon exposure have been exploited to develop a purine based biosensor. In order to use the immobilized purine nucleobases analytically as a biosensor, it is necessary to study the electrical processes that occur at the surface of the sensor. Out of the various techniques available, voltammetry and electrochemical impedance spectroscopy are the promising technique to study the immobilized purine bases. The electrochemical oxidation of guanine and guanosine at the electrode surface can be studied using differential pulse voltammetry. The film forming abilities of purines at the electrode surface can be studied from the diffusion of the redox ions from the electrolyte to the electrode surface using EIS and CV. In this report, the immobilized guanine and guanosine over MWCNT modified graphite electrode were studied using DPV, EIS and CV and further its interactions with the above mentioned benzene substituted organic compounds were analyzed. To our knowledge, this is the first report on the electrochemical characterization of guanosine and its application in the development of biosensor.

\section{Experimental}

All the electrochemical measurements were recorded using the instrument SP-300 from Biologic Science Instrument, France, running on EC-Lab Software (Version 10.18) and with standard calomel electrode as reference electrode, platinum wire as counter electrode and graphite electrode (surface area $=0.318 \mathrm{~cm}^{2}$ ) as working electrode. All the electrochemical measurements were conducted in a $20 \mathrm{~mL}$ cell containing $15 \mathrm{~mL}$ of the supporting electrolyte. The experimental procedure, modified electrode preparation and the immobilization of purines were performed using the same procedure as described in our earlier report ${ }^{12}$.

\section{Electrochemical determination of aromatic compounds}

The purine immobilized modified electrode was immersed in the solution containing various aromatic compounds for 5 minutes for the purines in the electrode to react with aromatic compounds. DPV and EIS measurements before and after the interaction with benzene substituted organic compounds were carried out. The relative percentage of survived purines 
after the analyte's interaction was calculated from the change of signals obtained at electrode with and without purines. This has been related to the difference of signals corresponding to that of original purines as follows:

$$
\begin{aligned}
\Delta \mathrm{I}_{\text {surv PN (rel) }} \% & =\left[\left(\mathrm{I}_{\text {surv purines }}-\mathrm{I}_{\mathrm{MWCNT}}\right) /\left(\mathrm{I}_{\mathrm{DNA}}-\mathrm{I}_{\mathrm{MWCNT}}\right)\right]^{* 100} \\
\Delta \mathrm{R}_{\mathrm{ct}(\mathrm{rel})} \% & =\left[\left(\mathrm{R}_{\mathrm{ct}(\text { surv } \mathrm{PN})}-\mathrm{R}_{\mathrm{ct}(\mathrm{MWCNT})}\right) /\left(\mathrm{R}_{\mathrm{ct}(\mathrm{PN})}-\mathrm{R}_{\mathrm{ct}(\mathrm{MWCNT})}\right)\right]^{*} 100
\end{aligned}
$$

Where $\mathrm{I}$ is the anodic peak current measured during DPV measurement in $0.1 \mathrm{M}$ phosphate buffer at the modified electrode without purines and $\mathrm{R}_{\mathrm{ct}}$ is the electron transfer resistance measured at the peak potential obtained for $10 / 10 \mathrm{mM} \mathrm{K}_{3} \mathrm{Fe}(\mathrm{CN})_{6} / \mathrm{K}_{4} \mathrm{Fe}(\mathrm{CN})_{6}$ in $0.1 \mathrm{M} \mathrm{NaCl}$ solutions at the modified electrodes without purine bases. The indexes used, characterize the chemical modifiers of graphite electrode ${ }^{13}$.

\section{Results and Discussion}

\section{Electrochemical oxidation of guanine and guanosine}

The electrochemical oxidation of guanine and guanosine at the modified graphite electrode followed a two step mechanism represented in the Figure 1. This involves a total loss of four electrons and the loss of first two electrons is the rate determining oxidation reaction. The oxidation of guanine and guanosine resulted in 8-oxo-guanine and 8-oxo-guanosine respectively ${ }^{14}$.

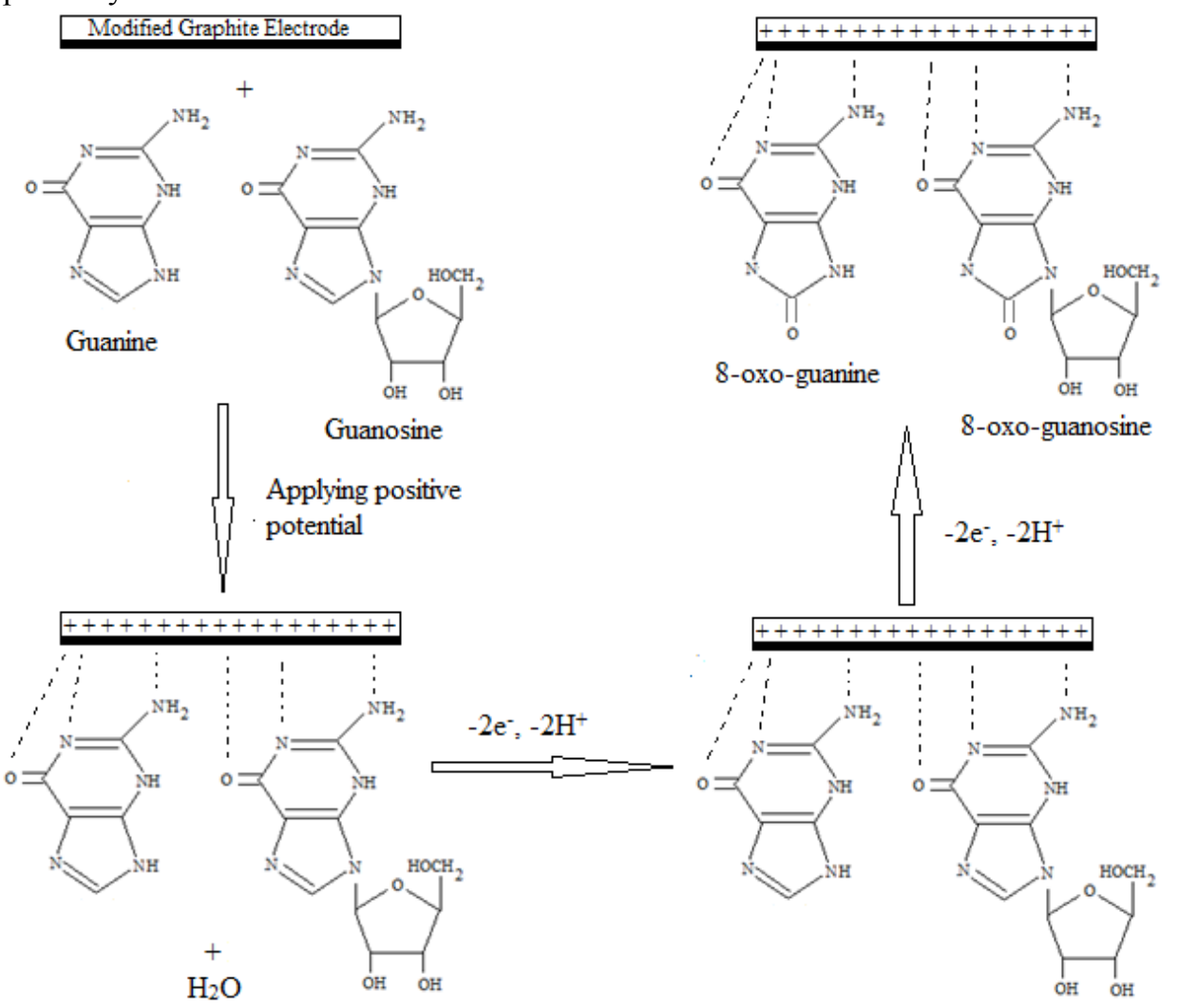

Figure 1. Scheme of the electrochemical oxidation of guanine and guanosine at the modified graphite electrode surface 


\section{Electron transfer characteristics at the electrode surface}

In order to study the interfacial electron transfer properties of the modified electrode immobilized with purine bases, EIS and CV were performed using the electroactive ferrocyanide/ferricyanide redox couple in $0.1 \mathrm{M} \mathrm{NaCl}$ solution. Nyquist plot of the working electrodes displays a semicircle at high frequencies and it is linear at low frequencies. The semicircle portion and the linear portion of the Nyquist plot represent electron transferlimited process and diffusion limited process respectively (Figure 2). MWCNT coated graphite electrode shows a small semicircle diameter indicating excellent conductivity of MWCNT. However, on the addition of purine bases, the electron transfer resistance increases but not greater than the electron transfer resistance of bare graphite electrode.

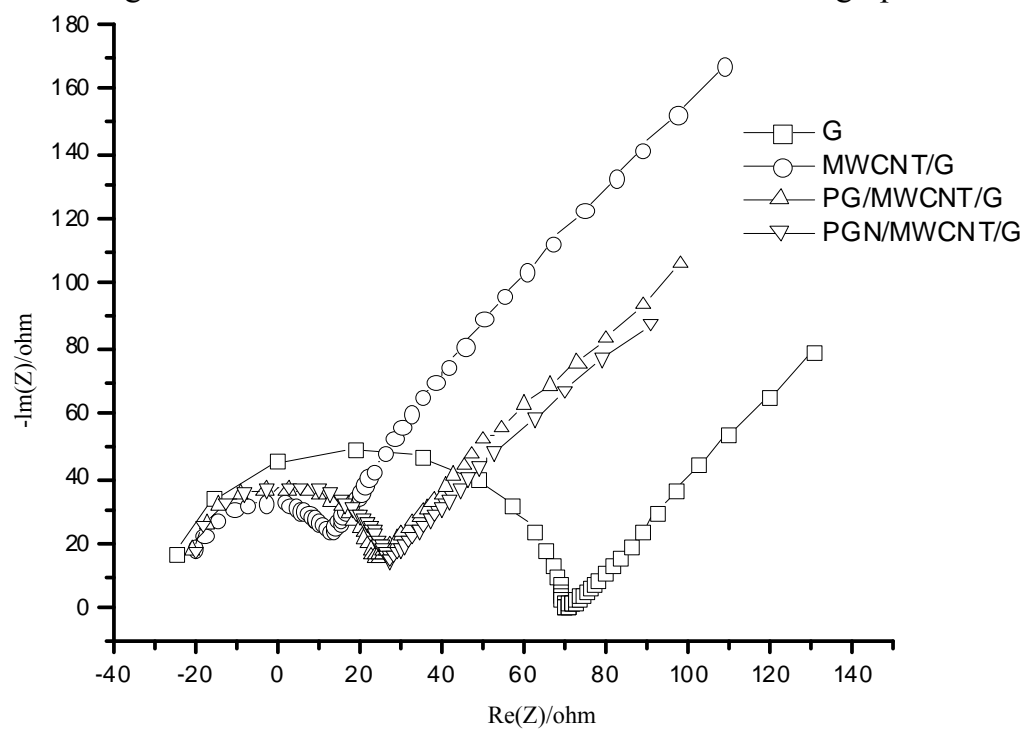

Figure 2. Nyquist plot for modified graphite electrodes in $0.1 \mathrm{M} \mathrm{NaCl}$

Nyquist plot of the modified electrodes represent a semicircle at high frequencies illustrating an electron transfer limiting process. For bare graphite, a short linear part of low frequencies are observed resulting from the diffusion of limiting step of the electrochemical process. It is important to consider the fact that this part of the spectrum represents the properties of the electrolyte solution and the diffusion of the redox couple in the supporting electrolyte and thus not affected by the modification of the electrode surface ${ }^{15}$. The impedence data were simulated using the Randles equivalent circuit consisting of a parallel combination of the capacitance $\left(\mathrm{C}_{\mathrm{dl}}\right)$ and the charge transfer resistance $\left(\mathrm{R}_{\mathrm{ct}}\right)$ redox reactions in series with the supporting electrolyte resistance $\left(\mathrm{R}_{\text {sol }}\right)$ (Figure 3$)$.

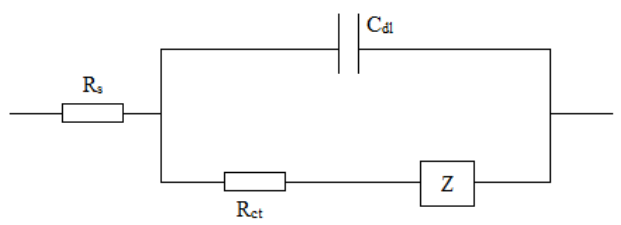

Figure 3. The scheme of equivalent circuit simulating the impedance spectra. $\mathrm{R}_{\mathrm{sol}}{ }^{-}$ resistance of the supporting electrolyte, $\mathrm{R}_{\mathrm{ct}^{-}}$charge transfer resistance, $\mathrm{C}_{\mathrm{dl}}$-capacitance. 
The increase or decrease in $\mathrm{R}_{\mathrm{ct}}$ reflecting the increase or decrease in the diameter of the semicircle is directly associated with the blockage behavior of the electrode surface for the charge transfer to the redox couple in the supporting electrolyte ${ }^{13}$. For bare graphite, the value of $R_{c t}$ is $70.38 \Omega$ and it reflects the semicircle part with greater diameter. As MWCNT is introduced to the graphite electrode, the diameter of the semicircle portion decreases, decreasing the $\mathrm{R}_{\mathrm{ct}}$ value till $13.39 \Omega$ (Table 1). As purine bases are introduced to the modified electrode, the charge transfer resistance of the redox probe increases. MWCNT immobilized on the graphite surface plays an important role similar to an electron conducting tunnel making electron transfer to the electrode surface easier. The increase in the $R_{c t}$ value for MWCNT electrode containing purines is due to the formation of highly organized layer of the purine bases over the modified electrode, resulting in the blockage of electron transfer to the redox couple, in other words, restricting the redox species to penetrate the MWCNT layer ${ }^{16}$. The electron transfer resistance of guanosine $(27.47 \Omega)$ is slightly greater than guanine $(22.39 \Omega)$. This could be due to the presence of ribose in the nucleosides resulting in decrease of electron transfer from the redox couple to the electrode.

Table 1. Parameters of the equivalent circuit simulating the complex impedance spectra of the electrodes in the presence of $0.1 \mathrm{M} \mathrm{NaCl}$ solution.

\begin{tabular}{cccc}
\hline Working Electrode & $\mathrm{R}_{\text {sol }}, \Omega$ & $\mathrm{R}_{\mathrm{ct}}, \Omega$ & $\mathrm{C}_{\mathrm{dl}}, \mu \mathrm{F}$ \\
\hline $\mathrm{G} / \mathrm{G}$ & -24.53 & 70.38 & 0.77 \\
MWCNT/G & -20.01 & 13.39 & 1873.6 \\
PG/MWCNT/G & -20.53 & 22.39 & 233.8 \\
PGN/MWCNT/G & -20.06 & 27.47 & 115.3 \\
\hline
\end{tabular}

$R_{\text {sol- }}$ Resistance of the supporting electrolyte, $R_{c t^{-}}$Charge transfer resistance, $C_{d l^{-}}$-capacitance

To confirm EIS, CV was performed in the same supporting electrolyte. The mechanism of purine bases detection using $\left[\mathrm{Fe}(\mathrm{CN})_{6}\right]^{3-} /\left[\mathrm{Fe}(\mathrm{CN})_{6}\right]^{4-}$ resides in the barrier effect of the purine bases towards the redox couple ${ }^{17}$, resulting in the reduction in redox couple signal (Figure 4) after the addition of purine bases to the modified electrode. The anodic to cathodic peak potential difference was $0.236 \mathrm{~V}$ for MWCNT modified electrode. The addition of MWCNT to the graphite electrode has increased the electrochemical reversibility of the redox couple. The addition of purine bases increases the peak potential difference and decreased the cathodic current. The $\Delta \mathrm{Ep}$ of guanine is slightly lesser than the the $\Delta \mathrm{Ep}$ of guanosine. This is due to the presence of ribose sugar which significantly block the redox ion transfer. This is in concordance with the result obtained for DPV in $0.1 \mathrm{M}$ phosphate buffer. Hence, the presence of other blockage compound places a major role in the transfer of electrons to the redox couple. In the case of MWCNT modified graphite electrode, the anodic to cathodic peak current was 1.01 confirming the reversibility of the redox probe. The presence of purines increases the peak potential value and decreases the cathodic current value and hence increasing Ia/Ic ratio. The peak potential difference and anodic to cathodic peak current ratio for different modified electrodes are summarized in Table 2.

\section{Electrochemical determination of benzene substituted derivatives}

Guanine and guanosine were attacked separately by exposing the modified electrodes to benzene substituted organic compounds. Survived purine bases were calculated from the DPV peaks and EIS spectra before and after the exposure. Figure 5a, 5b, 6a and $6 \mathrm{~b}$ display the calibration curves obtained from the average relative portion of survived purines using DPV and EIS respectively. Changes in purine oxidation and electron transfer resistance of the redox probe after the sensor exposure to $100 \mathrm{ng} / \mathrm{L}$ of the analyte is reprensented in Figure 7. 
As expected the percentage of survived purines were almost similar. This shows that the changes in the oxidation of the purine at the electrode surface is directly associated with the film forming abilities and electron transfer characteristics of the redox probe.

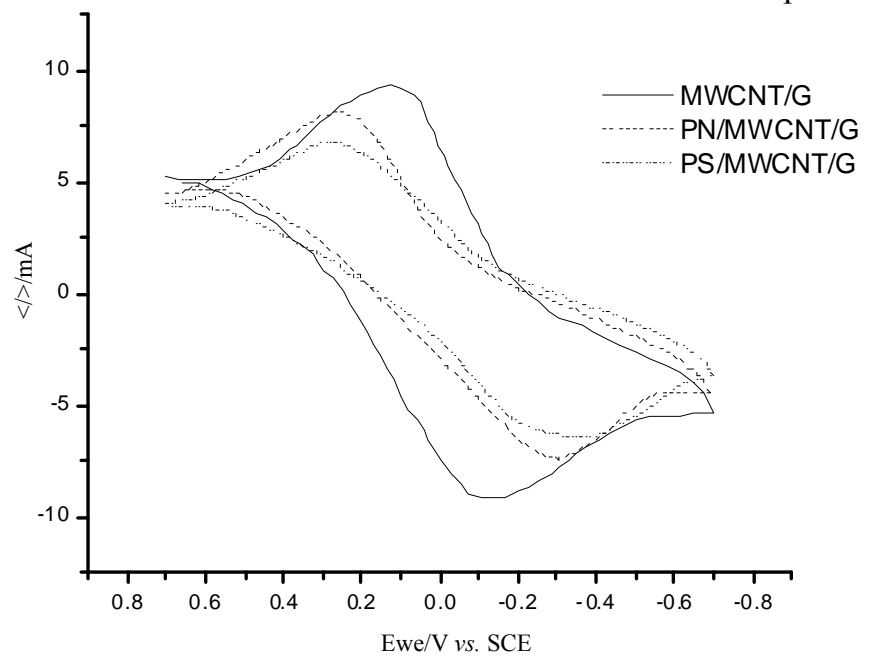

Figure 4. $\mathrm{CV}$ of the redox couple for the purine immobilized MWCNT modified graphite electrode

Table 2. CV parameters of modified electrode in $10 \mathrm{mM} \mathrm{K}_{4} \mathrm{Fe}(\mathrm{CN})_{6}+\mathrm{K}_{3} \mathrm{Fe}(\mathrm{CN})_{6}+0.1 \mathrm{M}$ $\mathrm{NaCl}(\mathrm{pH} 7)$ electrolyte

\begin{tabular}{ccc}
\hline Modified electrode & $\Delta \mathrm{Ep}, \mathrm{V}$ & $\mathrm{Ia} / \mathrm{Ic}$ \\
\hline $\mathrm{MWCNT} / \mathrm{G}$ & 0.236 & 1.01 \\
$\mathrm{PG} / \mathrm{MWCNT} / \mathrm{G}$ & 0.568 & 1.04 \\
$\mathrm{PGN} / \mathrm{MWCNT} / \mathrm{G}$ & 0.579 & 1.05 \\
\hline
\end{tabular}

$\triangle E p$ - anodic to cathodic peak potential difference, Ia/Ic-anodic to cathodic peak current ratio

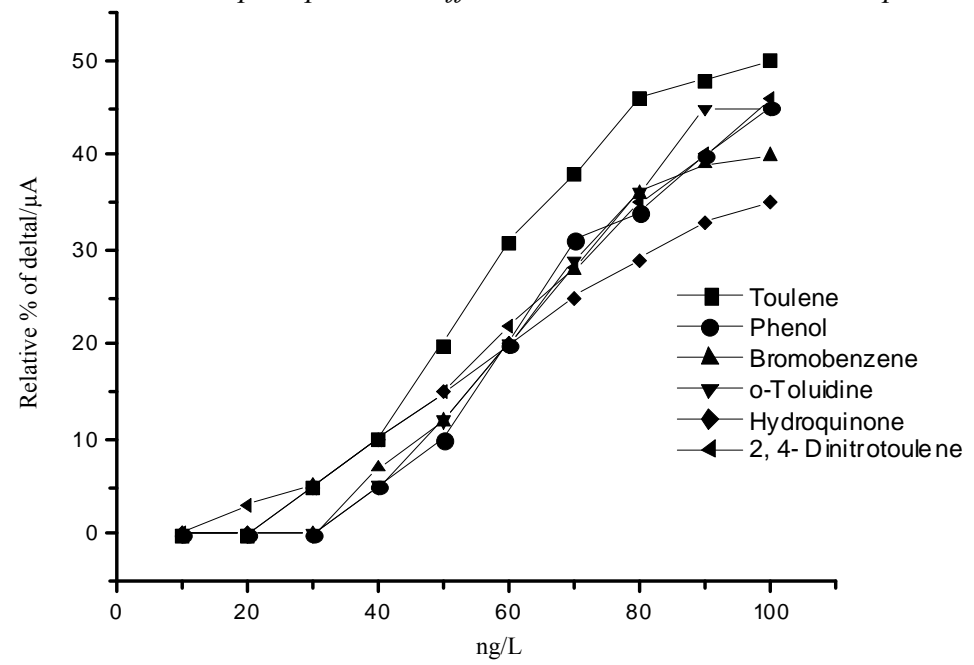

Figure 5a. Calibration curve obtained from the DPV measurements for the analyte's reaction with $\mathrm{PN} / \mathrm{MWCNT} / \mathrm{G}$ 


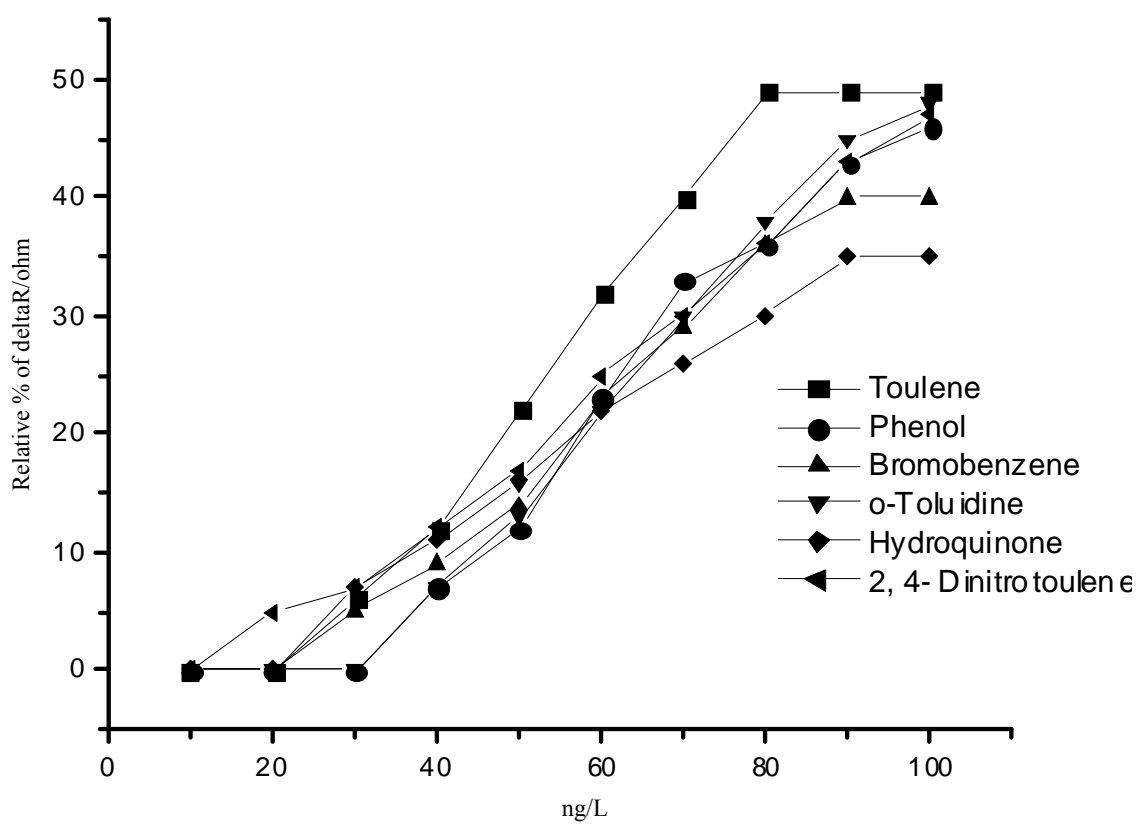

Figure 5b. Calibration curve obtained from the EIS measurements for the analyte's reaction with PN/MWCNT/G

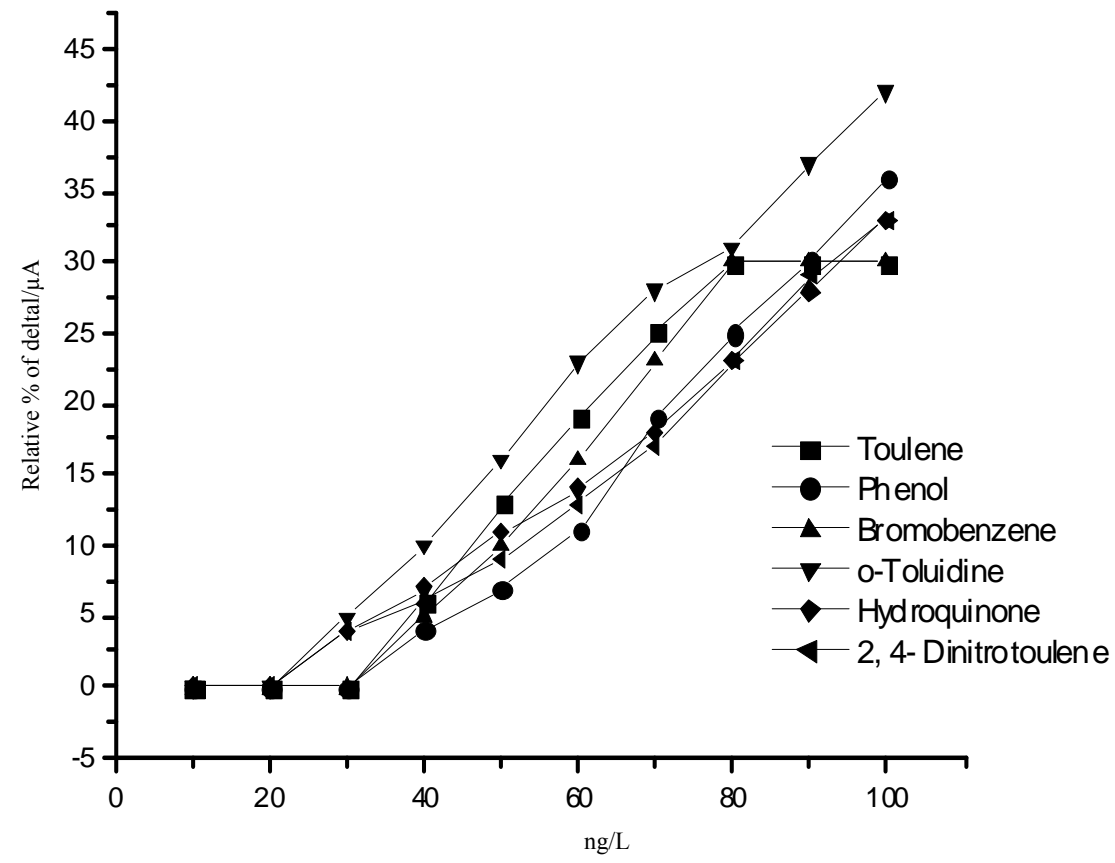

Figure 6a. Calibration curve obtained from the DPV measurements for the analyte's reaction with $\mathrm{PS} / \mathrm{MWCNT/G}$ 


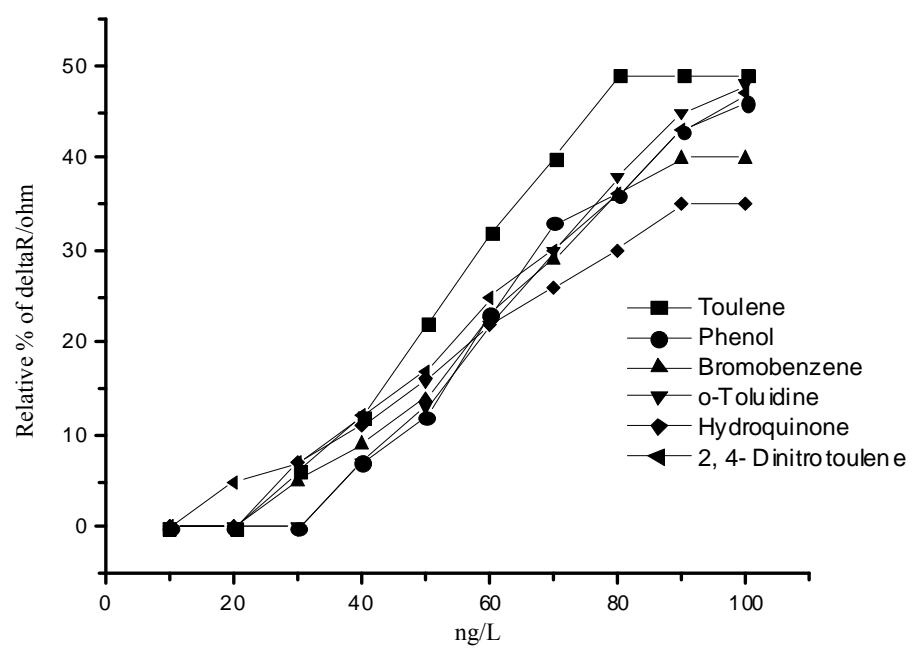

Figure 6b. Calibration curve obtained from the EIS measurements for the analyte's reaction with PS/MWCNT/G

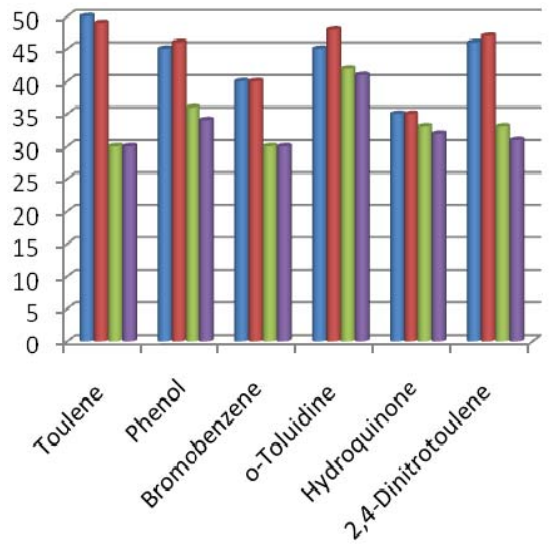

- DPV using PG/MWCNT/G

n EIS using PGN/MWCNT/G

a DPV using PG/MWCNT/G

- EIS using PGN/MWCNT/G

Figure 7. Relative percentage of the charge transfer resistance and current value obtained for the purine immobilized modified graphite for $100 \mathrm{ng} / \mathrm{L}$ of benzene substituted organic compound concentration.

\section{Conclusion}

MWCNT paste over the graphite electrode has ensured a good detection window for the voltammetric and impedimetric evaluation of the presence of guanine and guanosine. This is based on the oxidation profile obtained from DPV, the increase in the charge transfer resistance measured in EIS and the decrease in cathodic current due to the decrease of the voltammetric current of the negatively charge redox probe $\left(\left[\mathrm{Fe}\left(\mathrm{CN}_{6}\right)\right]^{3-}\right)$ for the purine immobilized graphite modified electrode.

\section{Acknowledgement}

The authors thank University Grants Commission, India, for its financial assistance and SRM University, India, for providing facilities for conducting this part of the experimental work. 


\section{References}

1. Downs M E A, Warner P J and Turner A P F, John C Fothergill, Biomaterials, 1988, 9(1), 66-70; DOI:10.1016/0142-9612(88)90072-5

2. Gu T and Hasebe Y, Biosens Bioelectron, 2006, 21(11), 2121-2128;

DOI:10.1016/j.bios.2005.10.007

3. Prabhakar N, Arora K, Singh H and Malhotra B D, J Phys Chem., 2008, 112(15), 4808-4816; DOI:10.1021/jp711853q

4. Yanez-Sedeno P, Riu J, Rius F X and Pingarron J M, TrAC Trends Anal Chem., 2010, 29(9), 939-953; DOI:10.1016/j.trac.2010.06.006

5. Nakai N, Murata M, Nagahama M, Hirase T, Tanaka M, Fujikawa T, Nakao N, Nakashima K and Kawanishi S, Free Radic Res., 2003, 37(1), 69-76.

6. Claycamp H G, Carcinogenesis, 1992, 13(7), 1289-1292; DOI:10.1093/carcin/13.7.1289

7. Wang $\mathrm{Y}$ F and $\mathrm{Hu} \mathrm{M}$ L, Food Chem Toxicol., 2000, 38, 451-458; DOI:10.1016/S0278-6915(00)00012-0

8. Yasuhiro O, Yusuke H, Shinji O, Naruto Y, Mariko M and Shosuke K, J Environ Pathol Toxicol., 1999, 2(2), 325.

9. Yunbo L and Michael A T, Carcinogenesis, 1993, 14(7), 1303-1311; DOI:10.1093/carcin/14.7.1303

10. Leanderson $\mathrm{P}$ and Tagesson C, Chem Biol Interact., 1990, 75(1), 71-81; DOI:10.1016/0009-2797(90)90023-G

11. Edilberto B, Deborah T and Byron E B, Environmental Mutagenesis, 1979, 1(4), 391 398; DOI:10.1002/em.2860010412

12. Gayathri S B, Kamaraj P and Arthanareeswari M, IJMCR, 2014, 2(2), 211-217.

13. Peng H, Soeller C, Vigar N A, Caprio V and Travas-Sejdic J, Biosens Bioelectron, 2007, 22(9-10), 1868-1873; DOI:10.1016/j.bios.2006.07.010

14. Dryhurst G, Electrochemistry of Biological Molecules; $1^{\text {st }}$ Ed.; Elsevier, 2012, Chapter 3.

15. Yang $\mathrm{L}$ and $\mathrm{Li} \mathrm{Y}$, Biosens Bioelectron, 2005, 20(7), 1407-1416; DOI:10.1016/j.bios.2004.06.024

16. Wang M, Wang L, Wang G, Ji X, Bai Y, Li T, Gong S and Li J, Biosens Bioelectron, 2004, 19, 575-582; DOI:10.1016/S0956-5663(03)00252-5

17. Galandova J, Ziyatdinova G and Labuda J, Anal Sci., 2008, 24, 6, 711-716. 